\title{
祝辞 Congratulations
}

In commemoration of the $50^{\text {th }}$ anniversary of the founding of the Atomic Energy Society of Japan (AESJ), it is my honor and privilege to deliver a congratulatory message to your Society and contribute in praise of your enthusiastic efforts for the energy independence during the last three decades in the special commemorative issue of ATOMOE.

I, not only as President of the Korean Nuclear Society (KNS) but also a fellow nuclear professional in a neighboring country, very highly appreciate your Society's endeavor in seeking academic and technical progress for the peaceful use of nuclear energy and contributing to the development and advancement of nuclear energy during the past five decades.

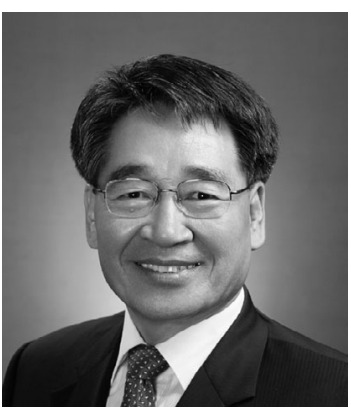

J. リー氏 Dr. Join-In LEE 韓国原子力学会 $(\mathrm{KNS})$ 会長 Hanyang大学で博士号取得。韓国原 子力研究所 (KAERI) 勤務を経て, 08 年から韓国原子力安全技術院 (KINS) 副院長。07年からはKNS会長を兼ね る。

After the Agreement for Co-operation between Atomic Energy Society of Japan and Korean Nuclear Society in 1999, Japan and Korea have closely cooperated with each other in many academic fields and areas such as Symposium on Nuclear Thermal Hydraulics and Safety (NTHAS), Korea-Japan Probabilistic Safety Assessment(KJPSA), Joint Session on nuclear materials technology, Cooperation between Japan Atomic Industry Forum(JAIF) and Korea Atomic Industry Forum (KAIF).

As we are all aware, Japan and Korea have been the two neighboring countries and the most enthusiastic devotees for the nuclear power in the North East Asian region. Constructing and operating more than one sixth of the total numbers of the nuclear power reactors in the world, the two countries have continuously aimed for achieving the energy independence from the earlier oil crisis in the $1970 \mathrm{~s}$ as well as paving the way to overcome the scarcity of the natural resources for the power generation. Recently, the neighboring countries in the North Eastern Asian region including China and India beside our two countries are desperately striving to become one of the world's biggest suppliers of the electricity generated by the nuclear power operations and high nuclear technology providers.

In this regard, the celebration of your Society on this very special occasion coming in February 2009 along with the $40^{\text {th }}$ anniversary of the Korean Nuclear Society (KNS), which is scheduled in May next year, will undoubtedly provide us with an excellent opportunity to appreciate our current rather stabilized energy situations in the two countries and assure of the utilization of the nuclear power to satisfy our growing needs for the green energy and power.

I believe, one of the most impending issues for the upcoming $21^{\text {st }}$ century centers on securing a reliable and continuing energy supply. This reliable and continuing supply 
will not only meet the growing demand on energy but also maintain the compatibility with the global environment that we preciously cherish.

This ultimate task has long since been discussed among the nations of common interests with a number of strategies being proposed to reach a common goal in general and to address the individual country's specific needs in particular. Thus, the strategies are unavoidably formulated based on individual country's specific philosophies and policies associated with the global environmental problems, potential energy resources, industrial technologies, economics, politics and so forth. In spite of the safety problems, which undermine the credibility and the public acceptance, nuclear energy is still expected to play a critical role in the worldwide electricity market in the coming centuries and millennia in Korea as well as in Japan. Advanced and next generation nuclear energy systems are being designed with much enhanced safety standards and the energy utilization capability.

Now, the cases of the Three Mile Island in the U.S. and Chernobyl accidents in Ukraine in 1979 and 1986, respectively, have made us clearly aware that there are essentially no borders in the nuclear safety issues. We can never overemphasize the importance of safe operations of the nuclear power plants from the technical, biological and ecological standpoints.

Japan and Korea stand very close in their eagerness in the development of nuclear technology and resolution of safety issues as well as in their geographical locations. Thus, it is to the mutual interest and benefit for the two countries to embark on vitalized technical as well as academic collaborations and communications.

I strongly believe that special anniversaries in the two countries next year shall be aimed at promoting the exchange of information on new findings, technical and academic achievements, and brand new concepts in the areas of nuclear sciences and technology.

Before closing my commemorative remark on your special occasion, I would like to introduce you on the KNS and its activities. The KNS was instituted in 1969 and is currently a home to more than 2,600 individual plenary and associate members and 41 corporate members covering a broad spectrum of academic educational institutions, research institutes and industries. The KNS not only publishes various nuclear related journals, NET (Nuclear Engineering and Technology), which was issued as a SCIE in 2006, and newsletters but also has been providing many forums for exchanging information, promoting collaborative R\&Ds, recognizing the members of outstanding achievements and awarding scholarship to young students. Besides, the various activities such as the professional training services, rejuvenate the young generation nuclear network, and inaugurate the student chapters are in service.

Finally, I hope the opportunity will be taken to build closer relations than before in terms of collaborations and communications through the two celebrations of both Societies.

Thank you very much.

（2008年 12 月10日 記） 